Research Article

\title{
Improvement of Automatic Calculation Method of CASE Bearing Capacity
}

\author{
Guosong Liu $(\mathbb{D})$ and Junlin Wang \\ Faculty of Water Science and Engineering, Zhengzhou University, Zhengzhou 450001, China \\ Correspondence should be addressed to Junlin Wang; junlinwang@zzu.edu.cn
}

Received 29 July 2021; Revised 15 August 2021; Accepted 17 August 2021; Published 29 August 2021

Academic Editor: Zhiyong Chen

Copyright (C) 2021 Guosong Liu and Junlin Wang. This is an open access article distributed under the Creative Commons Attribution License, which permits unrestricted use, distribution, and reproduction in any medium, provided the original work is properly cited.

\begin{abstract}
Because of the reliance on the empirical parameter CASE damping coefficient $J_{\mathfrak{c}}$, the high-strain CASE method is not recommended. The automatic bearing capacity calculation method RAU can avoid this, but it cannot be applied to friction piles. Based on the analysis of the automatic calculation method of bearing capacity RAU, considering the influence of pile side soil resistance unloading, this paper improved the RAU method through the influence of pile side soil damping on the velocity of the pile mass point during the stress wave propagation process. In this paper, we compare the collected static load test results of test piles with the improved automatic method results. The unary linear regression analysis is carried out with the help of statistical tools. The unary linear regression of the improved automatic method bearing capacity results on the static load test bearing capacity results is established. The improved automatic method solves the problem that the RAU method is only applicable to endbearing piles and can be applied to the quality analysis and bearing capacity calculation of the high-strain curve of the driven pile.
\end{abstract}

\section{Introduction}

The pile is a columnar member that penetrates the soil, which is the main foundation form at present. An important content of pile foundation inspection is the bearing capacity inspection. There are two main technical routes to determine the bearing capacity of pile foundations: the static load method and the high-strain measurement method $[1,2]$. In the static load method, the static load is set on the top of the foundation pile, and the Q-s curve and the bearing capacity of the foundation pile are obtained according to the applied static load and the measured pile settlement. The high-strain measurement method applies an impact load to the pile head and measures the stress and velocity-time history curve of the pile head to solve the bearing capacity of the pile by the wave theory.

The static load method test results are relatively more accurate and reliable. However, due to the long experiment period and high cost, the static load method can only select a few piles, and it is not easy to carry out large-scale inspections. Therefore, it is necessary to use a simple and fast high-strain dynamic test method as a supplement to the static load method.

The modern commonly used high-strain measurement method originated from the wave equation method proposed by Smith [3] in the 1960s. After years of theoretical development and experience accumulation, many theoretical routes have been innovated and improved [4-17], resulting in forming two common methods have been formed: the CASE method and the measured curve fitting method $[1,2]$. The CASE method is a closed solution method of the high-strain variation test method and simplifies the pile-soil conditions. It is assumed that the stress-strain relationship between the pile soil is ideally rigid and plastic, and the dynamic resistance is all concentrated on the pile tip, thereby decoupling the wave equation. This closed solution method is simple and fast and can generally provide realtime results on site, which is beneficial for pile driving monitoring and estimation of pile bearing capacity on site. The fitting method can be applied to more pile-soil conditions [18-31] and can simulate hysteresis damping, radiation damping, soil plugging effects, and various pile-soil 
nonlinear problems, but the analysis requires high-quality software and highly skilled personnel. Therefore, more time is required on the machine for analysis and generally can only be completed when the test is completed and returned to the room.

Due to its complexity, the fitting method cannot be used to determine whether there is any problem in the process of driving piles by monitoring the process of driving piles, and it is not easy to estimate the bearing capacity quickly at the project site. Therefore, the CASE method is difficult to be completely replaced by a fitting method. However, the key parameter of the CASE method CASE damping coefficient $J_{c}$ depends on human given, so many scholars have studied this.

In the 1970s, Rausche et al. $[5,6]$ concluded that the $J_{\mathrm{c}}$ value was related to the type of soil at the bottom of the pile through a large number of static and dynamic comparisons. The finer the soil particles, the larger the $J_{c}$ value. The suggested values of $J_{\mathrm{c}}$ for different pile bottom soils are given above [5]. Fellenius et al. $[32,33]$ concluded that the $J_{\mathrm{c}}$ value of the CASE method is related to the type of pile, the test site, and the pile driving resistance through a dynamic and static comparison of four prefabricated steel piles in moraine soil. Holm et al. [34] compared the static and dynamic prestressed square piles in loose sand and found that the average value of $J_{\mathrm{c}}$ should be twice as high as that recommended by the PDI company established by Goble et al. Thompson and Goble [35] further found that if the $J_{c}$ value is selected according to the general recommendations, the dynamic resistance in the sand is likely to be significantly underestimated, and the bearing capacity is too high. Although Wong [36] agreed that the CASE damping coefficient mainly depends on the type of soil below the pile and found that the actual selection of the $J_{c}$ value was different from the recommended value in the United States, therefore, he believed that more dynamic and static comparisons are needed to reasonably select the $J_{\mathrm{c}}$ value.

Chinese scholars have also studied this topic. Chen [37] pointed out that when there is a lack of regional experience, long piles, large-diameter cast-in-place piles, and so on, due to their own characteristics and possible construction problems, it may affect the corresponding $J_{c}$ value and reduce the accuracy of the bearing capacity judgment. Zai [38] believed that the $J_{\mathrm{c}}$ value is related to the dissipation of stress wave energy during propagation. Generally speaking, the longer the pile length, the higher the pile internal resistance and the greater the $J_{c}$ value. Liwen [39] found that if the actually exciting pile displacement does not reach the elastic limit, the $J_{\mathrm{c}}$ value is related to the pile displacement. Ju [40] believed that the $J_{\mathrm{c}}$ value is also related to the geometry and size of the pile. $\mathrm{Wu}$ [41] pointed out that the $J_{\mathrm{c}}$ value of piles in soft soils should usually be appropriately increased to eliminate part of the side resistance.

Gradually, more and more people doubt whether the CASE damping coefficient has a clear physical meaning. Zhang and Sun [42] pointed out that the impedance $Z$ in the definition of $J_{\mathrm{c}}$ is related to the state of the pile, so $J_{\mathrm{c}}$ cannot be only related to the nature of the soil at the bottom of the pile. According to the derivation of the formula, Liwen [39] found that $J_{\mathrm{c}}$ was essentially only the ratio of the dynamic resistance to the total resistance, so as long as there is nonnegligible lateral resistance, the $J_{c}$ value cannot be completely determined by the soil properties. Li [43] further pointed out that the approximate assumption of CASE is the key to the large variation range of the CASE damping coefficient and the ambiguity of its physical meaning. Xie [44] also agreed that there are contradictions between the approximate assumptions of the CASE method and its derivation process. To and Smith [45] found that the CASE damping coefficient $J_{\mathrm{c}}$ cannot be backanalyzed as a simple constant, which means that $J_{\mathrm{c}}$ must contain dynamic effects. Tchepak [46] also believed that changes in the actual pile-soil and construction techniques can affect $J_{\mathrm{c}}$. Paikowsky and Stenersen [47] conducted a statistical analysis of the dynamic and static comparisons of various types of driven piles collected in the PD/LT-2000 database and found that the $J_{\mathrm{c}}$ value varies greatly, and many data seriously exceed the normal range of values. Despite so many years of development, the selection of the $J_{\mathrm{c}}$ value still relies heavily on the experience of the inspector.

In order to avoid the error caused by selecting the $J_{c}$ value based on experience, the American PDI (Pile Dynamics, Inc.) company has been trying to find an algorithm to eliminate the dynamic resistance of the soil automatically and directly obtain the static resistance called bearing capacity. Automatic calculation method [7] is referred to as automatic method. Goble et al. proposed an automatic method suitable for end-bearing piles, which is represented by the computer symbol RAU. On the basis of RAU, this paper revised the RAU method through the analysis of RAU and the derivation of its influence on pile side resistance, making it able to be applied to friction piles, and its effectiveness is verified by statistical methods.

\section{The Basic Theory of Wave Equation}

Considering the pile as a one-dimensional continuous elastic bar, its vibration equation is

$$
\frac{\partial^{2} u}{\partial t^{2}}-C^{2} \frac{\partial^{2} u}{\partial x^{2}}=0,
$$

where $u(x, t)$ is the displacement of pile mass; $C=\sqrt{E / \rho}$ is the velocity of the stress wave; $E$ is the elastic modulus; $\rho$ is the density of pile body. By solving the equation, the travelling wave theory shows that the propagation of the stress wave can be regarded as the superposition of the ascending wave and the descending wave in the pile shaft.

The CASE method makes three basic assumptions as follows:

(1) The pile body impedance is constant; except for the constant section, the pile body material is uniform without obvious defects.

(2) When the stress wave propagates along with the pile, there is no energy loss or waveform distortion caused by other factors except the influence of soil resistance. 
(3) Only the dynamic damping of the soil at the bottom of the pile is considered and the dynamic damping of the soil at the side of the pile is ignored, and the static resistance is always constant. The static resistance of the soil to the pile has nothing to do with the displacement between the pile and soil but is only related to the existence of the relative displacement between the pile and soil.

Based on these three basic assumptions, the CASE calculation expression of the ultimate bearing capacity was derived using the travelling wave theory and wave equations to derive:

$$
\begin{aligned}
R= & R_{t}-J_{t} Z V(L, t) \\
= & \left(1-J_{c}\right) \frac{\left[F\left(t_{1}\right)+Z V\left(t_{1}\right)\right]}{2}+\left(1+J_{c}\right) \\
& \times \frac{\left[F\left(t_{1} 2 L / C\right)-Z V\left(t_{1}+2 L / C\right)\right]}{2},
\end{aligned}
$$

where $R_{t}$ is the total resistance; $Z=\rho C A$ is pile impedance; $t_{1}$ is the first calculation time and is generally the peak time of the velocity curve; and $J_{c}$ is the CASE damping coefficient, generally related to the type of pile subsoil, which can be selected within a scope according to the actual situation. Rausche et al.'s recommendations are shown in Table 1 [5].

The CASE method assumes that the dynamic resistance is concentrated at the bottom of the pile. If the dynamic resistance on the side of the pile is indeed negligible, and the dynamic resistance is always proportional to the speed of the pile interface, then the dynamic resistance will not exist when the speed of the bottom of the pile is zero, RAU can be obtained. Based on this, when the bottom velocity of the pile is zero, the total dynamic resistance of the whole pile will be the static resistance; as long as the static resistance of all sections of the pile body is at its maximum value, the limit of the whole pile can be directly obtained. The pile tip velocity is

$$
V_{b}(t)=\frac{1}{2 Z}\left[F\left(t_{1}\right)+Z V\left(t_{1}\right)-F\left(t_{1}+\frac{2 L}{C}\right)+Z V\left(t_{1}+\frac{2 L}{C}\right)\right]
$$

The ultimate bearing capacity is the ultimate bearing capacity of the pile when velocity in (3) is equal to zero, and the influence of $J_{c}$ will disappear completely.

It is apparently only when the pile is completely moved, the soil resistance at the side of the pile has little effect, the resistance of the soil does not decrease significantly, and the unloading of the soil at the side of the pile is not obvious that this value is suitable. In fact, it is easy to prove that when it is an end-bearing pile, the soil resistance on the side of the pile is almost zero, so when the speed of the pile tip is zero, the displacement and the static resistance are maximum. Therefore, at this time, the exact solution of bearing capacity is the maximum ultimate bearing capacity stimulated. For friction piles, when the pile tip speed is zero, due to the wave effect, the pile body's speeds have been negative values, and the pile side soil has been unloaded. Unloading of the pile body caused the side resistance to decrease or even negative resistance, thus, offset to 0 . Only in the upper and lower wave superimposed area of the pile body, due to the late unloading, the speed is slow, and there is still a certain lateral resistance. That is to say, the pile side soil resistance assumed by the RAU method can only be maintained near the pile tip, and the residual total resistance of the upper soil layer can be ignored due to unloading. Therefore, the soil resistance obtained by the RAU method is almost only the static soil resistance near the pile end, so we can use the static soil resistance on the upper side of the pile to modify the RAU method.

\section{The Influence of Pile Side Soil Resistance on the Movement Speed of Pile Mass}

Considering the influence of the pile side soil resistance [7], only the uniform foundation is considered here for the convenience of calculation, and the multilayer foundation is regarded as the superposition of multiple uniform foundations. Assuming that the pile is completely moved, adequate displacement is generated everywhere in the pile body, and the static resistance can is fully exerted. Before the stress wave propagates to the pile tip, the damping effect of the soil around the pile can be divided into two parts: static resistance using the static and plastic model and dynamic resistance using Newtonian viscous body model; the resistance per unit length of the pile body is

$$
R=R_{s}+\eta \cdot Z \cdot V
$$

where $R_{s}$ is the static resistance; $V$ is the mass velocity; $\eta$ is the damping coefficient. If the pressure and compression deformation are positive and the pile constitutive relation satisfies Hooke's law, the governing equation can be obtained:

$$
\left\{\begin{array}{l}
V==-\dot{\varepsilon}, \\
F=A E \varepsilon, \\
\rho A \dot{V}=-F^{\prime}-R_{s}-\eta Z V,
\end{array}\right.
$$

where "'"means taking the derivative of space; "." represents the derivative with respect to time, so the corresponding characteristic line and compatibility relation are

$$
\left\{\begin{array}{l}
\mathrm{d} x= \pm C \mathrm{~d} t, \\
\mathrm{~d} F=\mp Z \mathrm{~d} V-R_{s} \mathrm{~d} x-\eta Z V \mathrm{~d} x .
\end{array}\right.
$$

For discontinuous waves, it still has

$$
\left\{\begin{array}{l}
\mathrm{d} x= \pm C \mathrm{~d} t \\
{[F]= \pm Z[V] .}
\end{array}\right.
$$

After combining (6) and (7), the following can be obtained:

$$
\mathrm{Zd} V=-Z \mathrm{~d} V-R_{s} \mathrm{~d} x-\eta Z V \mathrm{~d} x .
$$

It can be transformed as 
TABLE 1: Goble et al.'s recommendations for $J_{\mathrm{c}}$ selection.

\begin{tabular}{lcccc}
\hline Type of pile subsoil & Pure sand & Silty sand and sandy silt & Silt & Silty clay and clay silt \\
\hline$J_{\mathrm{c}}$ scope & $0.05 \sim 0.20$ & $0.15 \sim 0.30$ & $0.20 \sim 0.45$ & $0.40 \sim 0.70$ \\
\hline
\end{tabular}

$$
2 \frac{\mathrm{d} V}{\mathrm{~d} x}+\eta V+\frac{R_{s}}{Z}=0
$$

This is an ordinary differential equation of first order. If the initial particle vibration velocity of each ground layer is $V_{0}$, then its solution is

$$
V(x)=\left(V_{0}+\frac{R_{s}}{\eta Z}\right) e^{-(\eta / 2) x}-\frac{R_{s}}{\eta Z}
$$

This is an exponential function. Equation (10) shows that when the pile is completely moved, during the propagation of the stress wave, the peak velocity of the particles decays approximately exponentially as the depth increases.

\section{Automatic Method of Bearing Capacity considering Soil Resistance of Pile Side}

When the wave propagates to the pile tip, if the influence of the attenuation of the pile body internal resistance and the change of the pile side dynamic resistance with time is not considered, for any point $e$ of the pile body, $E$ is the time when the pile top corresponds to point $e$ along the characteristic line. After propagating to point $e$ for the first time, according to the feature line and the compatibility relationship on the feature line, the following equation can be derived:

$$
\left\{\begin{array}{l}
F_{1}+Z V_{1}=F_{e}+Z V_{e}+R \\
F_{E}-Z V_{E}=F_{e}-Z V_{e}+R
\end{array}\right.
$$

where $F_{1}, V_{1}$ are in the initial downlink wave state; $F_{\mathrm{e}}, V_{e}$ is point $e$ state; $R$ is the soil limit resistance above point $e$. During stress wave propagation, the pile velocity can be easily obtained:

$$
V(x)=V_{e}=\frac{1}{2 Z}\left(F_{1}+Z V_{1}-F_{E}+Z V_{E}\right) .
$$

Then, the computable expression form is

$$
V(x)=\frac{1}{2 Z}\left[f\left(t_{1}\right)+Z V\left(t_{1}\right)-f\left(t_{1}+\frac{2 x}{C}\right)+Z V\left(t_{1}+\frac{2 x}{C}\right)\right] \text {. }
$$

Based on (13) and (10) combined with the formation situation, the reflected take-off point of the interval ending at the pile bottom can be calculated. After data fitting or substitution calculation, each stratum's average unit pile side static resistance value $R_{s i}$ and dynamic damping coefficient $\eta_{i}$ can be obtained. The lateral resistance of the superposition area of upstream and downstream waves under the pile body has been included in the RAU method, so it is not calculated here.
Thus, the total soil static resistance on the upper side of the pile can be obtained:

$$
R_{s s}=\sum R_{s i} \cdot L_{i}
$$

where $L_{i}$ is the thickness of the $i$ th layer of foundation soil. The total static resistance is

$$
R_{s}=R A U+R_{s s} .
$$

\section{Comparison of Automatic Method Results and Static Load Results}

Based on the above theoretical derivation, the author selected some of the piles from the dynamic test of the China Steel Metal Products Quality Supervision and Inspection Center and some documents [48] to be completely moved by the heavy hammer, in which the pile body was not unloaded prematurely, and the pile bottom reflection was obvious. The driven piles are automatically calculated by the improved method in this paper. Moreover, the static load test results were analyzed by SPSS with one-variable linear regression [49]. The result of the automatic method is used as the independent variable, and the result of the static load test is used as the dependent variable. Because of the high accuracy of the static load test, the analysis results can be judged whether the results of the automatic bearing capacity calculation method in this paper can be used to predict the actual ultimate bearing capacity of the pile. The scatter plot of the ultimate bearing capacity results is shown in Figure 1.

The ratio statistics for automatic versus static methods are shown in Table 2.

The regression analysis results are shown in Tables 3 and 4.

The studentized residual plot is shown in Figure 2.

The regression equation can be obtained as $\hat{y}=1.113 x-222.745$. Among them, the regression coefficient $\beta_{1}=1.113$, the regression coefficient is close to 1 , and the tested $t$ value is 22.992 , Sig. $\leq 0.001$, suggesting that the regression coefficient is highly significant, and the static load test results are consistent with the unitary linear regression of the results calculated by the automatic method. As can be seen from Figure 2, all points are in the range of $(-3,3)$ and there are no outliers. This indicates that the static resistance calculated by the automatic method in this paper is in good agreement with the static resistance obtained by the static load test, and the improved automatic method can be used to predict the ultimate bearing capacity of the pile foundation.

Because the distribution of residuals in the residual graph is abnormal, the curve regression is used to analyze and confirm again. The quadratic curve was used for regression analysis and compared with linear regression. The results of quadratic regression analysis are shown in Tables 5 and 6 , and the model fitting diagram is shown in Figure 3. 


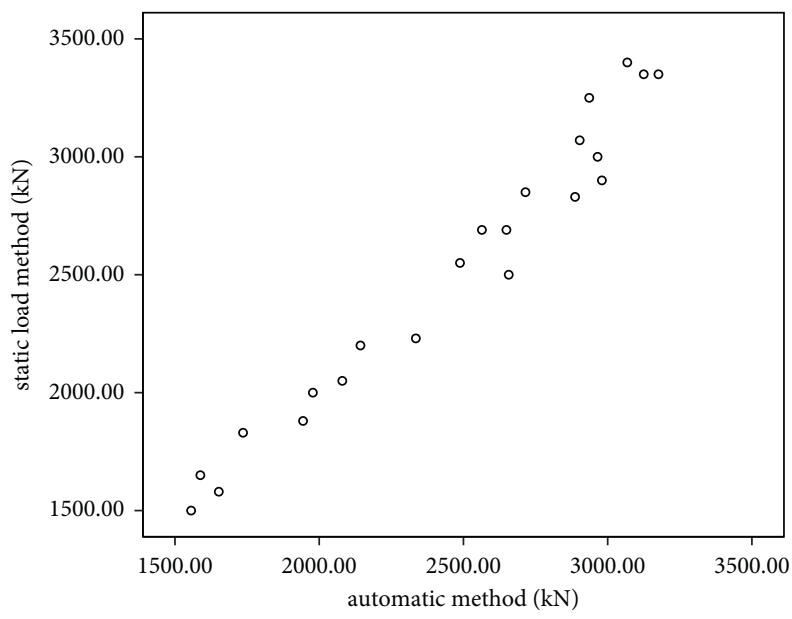

FIGURE 1: The bearing capacity relationship between automatic method and static load method.

TABLE 2: Ratio statistics.

\begin{tabular}{lccccc}
\hline Mean value & Median & Minimum & Maximum & Standard deviation & Coefficient of variation \\
\hline 0.984 & 0.980 & 0.902 & 1.063 & 0.047 & 0.040 \\
\hline
\end{tabular}

TABle 3: Anova.

\begin{tabular}{lcccc}
\hline Model & Sum of squares & df & Mean square & $F$ \\
Regression & 7583612.335 & 1 & 7583612.335 & 528.623 \\
Residual & 286919.483 & 20 & 14345.974 & $<0.001$ \\
Total & 7870531.818 & 21 & & \\
\hline
\end{tabular}

Table 4: Coefficients.

\begin{tabular}{lcccr}
\hline \multirow{2}{*}{ Model } & \multicolumn{2}{c}{ Unstandardized coefficients } & Standardized coefficients & $t$ \\
& $B$ & Std. error & Beta & Sig. \\
\hline (Constant) & -222.745 & 121.821 & & -1.828 \\
$x$ & 1.113 & 0.048 & 0.982 & 22.992 \\
\hline
\end{tabular}

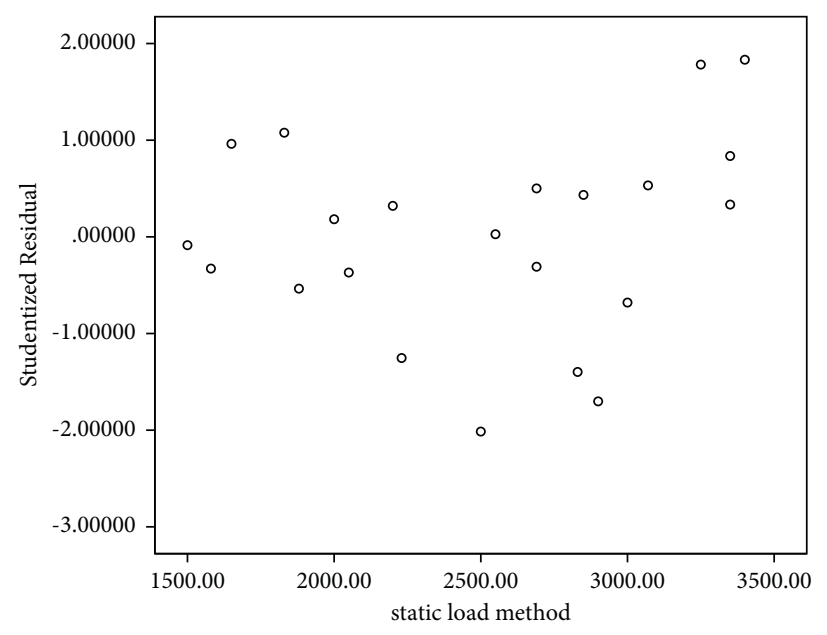

Figure 2: Studentized residual plot. 
Table 5: Anova.

\begin{tabular}{lcccr}
\hline & Sum of squares & df & Mean square & $F$ \\
\hline Regression & 7616015.500 & 2 & 3808007.750 & 284.273 \\
Residual & 254516.318 & 19 & 13395.596 & $<0.001$ \\
Total & 7870531.818 & 21 & & \\
\hline
\end{tabular}

TABLE 6: Coefficients.

\begin{tabular}{|c|c|c|c|c|c|}
\hline & \multicolumn{2}{|c|}{ Unstandardized coefficients } & \multirow{2}{*}{$\begin{array}{c}\text { Standardized coefficients } \\
\text { Beta }\end{array}$} & \multirow{2}{*}{$t$} & \multirow{2}{*}{ Sig. } \\
\hline & $B$ & Std. error & & & \\
\hline$x$ & 0.276 & 0.540 & 0.244 & 0.512 & 0.615 \\
\hline$x * * 2$ & $<0.001$ & $<0.001$ & 0.741 & 1.555 & 0.136 \\
\hline Constant & 715.047 & 614.351 & & 1.164 & 0.259 \\
\hline
\end{tabular}

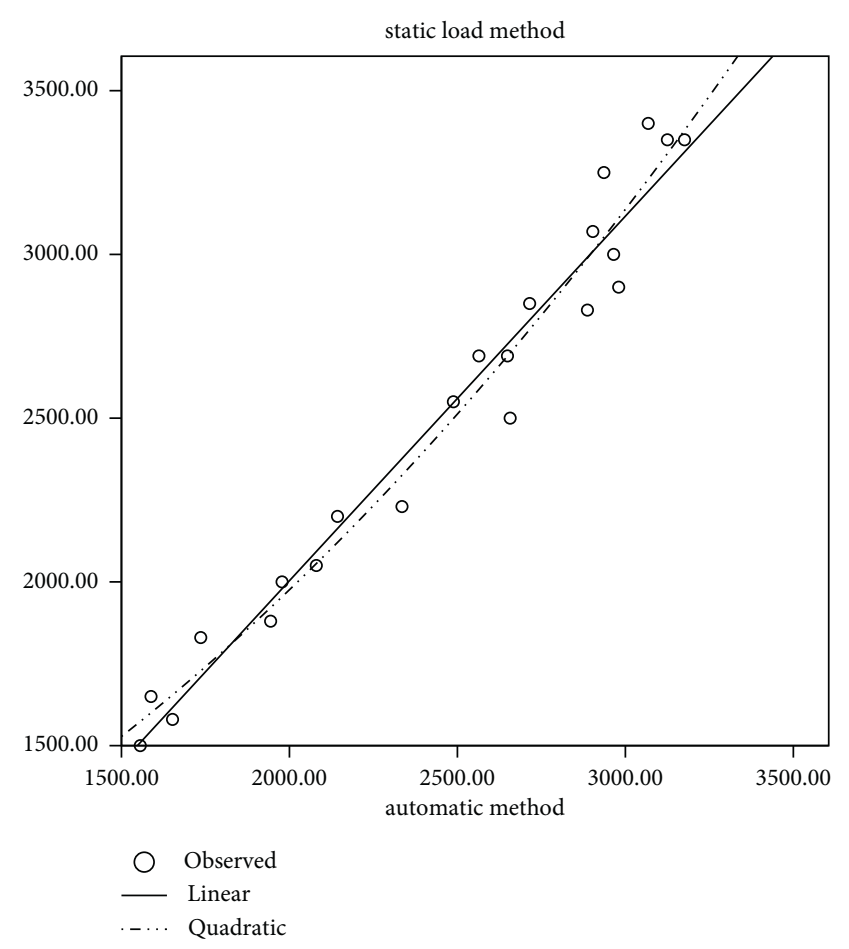

Figure 3: Model fitting diagram.

According to Table 3, the linear regression $\mathrm{SSE}=286919.483$, SST $=7870531.818$. According to Table 5, the quadratic curve regression $\mathrm{SSE}=254516.318$, SST $=7870531.818$. So, the coefficient of determination of the linear regression is less than that of the quadratic curve. It can be inferred that the fitting effect of the quadratic curve is better than that of linear regression. This means that with the increase of ultimate bearing capacity of the pile, the use of an improved automatic method will underestimate the bearing capacity. The reason for the analysis may be that the lateral friction resistance of the pile with high bearing capacity is relatively large in the pile as the data source in this paper. This indicates that when the lateral friction resistance of the pile is very large, the automatic method results in this paper will significantly underestimate the ultimate bearing capacity.

\section{Conclusions}

(1) For the pile that is completely moved by the heavy weight and can produce sufficient penetration, the relationship between the velocity of the pile mass and the depth of the stress wave peak is an exponential function. Based on this relationship and the formula of the velocity of the pile mass, the ultimate static resistance of the soil around the pile can be obtained. Thus, the improved RAU automatic bearing capacity can be obtained.

(2) In this paper, the results of the method in the improvement of the static load test results of regression effect are very good; this is because the regression coefficient is close to 1 , and a good regression coefficient is 1 , which means in this paper, the improved method of automatic static resistance is almost equal to the ultimate bearing capacity of the pile in this paper. The results of the improved method can be used automatically for driven pile bearing capacity estimation, the monitoring and controlling of the pile driving, and could be used to judge the quality of the high-strain dynamic test acquisition curve.

(3) The improved automatic method is not suitable for piles with high bearing capacity, especially high side resistance.

(4) In order to more accurately judge the effectiveness of the method for more pile types, it is better to conduct more data analysis.

\section{Data Availability}

The permeability and dissolution data used to support the findings of this study are included in the article. The foundation pile testing data used to support the findings of this study were supplied by Junlin Wang under license and so cannot be made freely available.

\section{Conflicts of Interest}

The authors declare that there are no conflicts of interest regarding the publication of this paper. 


\section{Acknowledgments}

This research was funded by the National Natural Science Foundation of China, Grant no. 51978630.

\section{References}

[1] MOHURD, JGJ106 - 2014, Technical Code for Testing of Building Foundation Piles, China Architecture \& Building Press, Beijing, China, 2014.

[2] ASTM, D4945-17, Standard Test Method for High-Strain Dynamic Testing of Deep Foundations, America, New York, NY, USA, 2012.

[3] E. A. L. Smith, "Pile-driving analysis by the wave equation," Journal of the Soil Mechanics and Foundations Division, vol. 86, no. 4, pp. 35-61, 1960.

[4] P. W. Forehand and J. L. Reese, "Prediction of pile capacity by the wave equation," Journal of the Soil Mechanics and Foundations Division, vol. 90, no. 2, pp. 1-25, 1964.

[5] F. Rausche, G. G. Goble, and G. E. Likins, "Dynamic determination of pile capacity," Journal of Geotechnical Engineering, vol. 111, no. 3, pp. 367-383, 1985.

[6] F. Rausche, F. Moses, and G. G. Goble, "Soil resistance predictions from pile dynamics," Journal of the Soil Mechanics and Foundations Division, SM9, vol. 98, no. 9, pp. 917-937, 1972.

[7] X. Wang and S. Wu, Dynamic Measurement Technology of Foundation Pile, science press, Beijing, China, 2001.

[8] X. Hu, S. Ma, and K. Wang, "Influence of positions of sensor on results measured on a high strain pile," Journal of Vibration and Shock, vol. 30, no. 4, pp. 259-264, 2011.

[9] Y.-g. Zhang, J. Tang, Z.-y. He, J. Tan, and C. Li, "A novel displacement prediction method using gated recurrent unit model with time series analysis in the Erdaohe landslide," Natural Hazards, vol. 105, no. 1, pp. 783-813, 2020.

[10] X. Ma, G. Zhu, L. Liu et al., "Response of saturated clay ground during pile driving," Chinese Journal of Rock Mechanics and Engineering, vol. 39, no. 1, pp. 205-216, 2020.

[11] W. Jiang, G. Zhu, and J. Zhang, "A direct high-strain method for the bearing capacity of single piles," Rock and Soil Mechanics, vol. 41, no. 10, pp. 3500-3508, 2020.

[12] Y. Zhang and L. Yang, "A novel dynamic predictive method of water inrush from coal floor based on gated recurrent unit model," Natural Hazards, vol. 105, no. 2, pp. 2027-2043, 2020.

[13] X. Liu, S. Song, Y. Tan et al., "Similar simulation study on the deformation and failure of surrounding rock of a large section chamber group under dynamic loading," International Journal of Mining Science and Technology, vol. 31, no. 3, pp. 495-505, 2021.

[14] Y. G. Zhang, Z. Zhang, and S. Xue, "Stability analysis of a typical landslide mass in the Three Gorges Reservoir under varying reservoir water levels," Environmental Earth Sciences, vol. 79, no. 1, pp. 1-14, 2020.

[15] Y. G. Zhang, S. Y. Zhu, J. K. Tan, L. Li, and X. Yin, "The influence of water level fluctuation on the stability of landslide in the Three Gorges Reservoir," Arabian Journal of Geosciences, vol. 13, no. 17, 2020.
[16] H. Jing, J. Wu, Q. Yin, and K. Wang, "Deformation and failure characteristics of anchorage structure of surrounding rock in deep roadway," International Journal of Mining Science and Technology, vol. 30, no. 5, pp. 593-604, 2020.

[17] Y. G. Zhang, S. Y. Zhu, W. Q. Zhang, and H. Liu, "Analysis of deformation characteristics and stability mechanisms of typical landslide mass based on the field monitoring in the Three Gorges Reservoir, China," Journal of Earth System Science, vol. 128, no. 1, p. 1, 2019.

[18] A. E. Holeyman, "Dynamic non-linear skin friction of piles," in Proceedings of the international Symposium on Penetrability and Drivability of Piles, vol. 1, pp. 173-176, San Francisco, CA, USA, August 1985.

[19] M. F. Randolph, "Modeling of the soil plug response during pile driving," in Proceedings of the 9th Southeast Asian Geotechnical Conference, Bangkok, Thailand, December 1987.

[20] S. L. Lee, Y. K. Chow, G. P. Karunaratne, and K. Y Wong, "Rational wave equation model for pile-driving analysis," Journal of Geotechnical Engineering, vol. 114, no. 3, pp. 306-325, 1988.

[21] R. Salgado, D. Loukidis, G. Abou-jaoude, and Y. Zhang, "The role of soil stiffness non-linearity in $1 \mathrm{D}$ pile driving simulations," Géotechnique, vol. 65, no. 3, pp. 169-187, 2015.

[22] X. Hao, W. Du, Y. Zhao et al., "Dynamic tensile behaviour and crack propagation of coal under coupled static-dynamic loading," International Journal of Mining Science and Technology, vol. 30, no. 5, pp. 659-668, 2020.

[23] Z. Zhang, M. Deng, J. Bai, S. Yan, and X. Yu, "Stability control of gob-side entry retained under the gob with close distance coal seams," International Journal of Mining Science and Technology, vol. 31, no. 2, pp. 321-332, 2020.

[24] Y. Zhang, Y. Xie, Y. Zhang, J. Qiu, and S. Wu, “The adoption of deep neural network (DNN) to the prediction of soil liquefaction based on shear wave velocity," Bulletin of Engineering Geology and the Environment, vol. 80, no. 6, pp. 5053-5060, 2021.

[25] Y. G. Zhang, J. B. Qiu, Y. Zhang, and Y. Y. Wei, "The adoption of ELM to the prediction of soil liquefaction based on CPT," Natural Hazards, vol. 107, no. 1, pp. 539-549, 2021.

[26] Y. G. Zhang, X. Q. Chen, R. P. Liao et al., "Research on displacement prediction of step-type landslide under the influence of various environmental factors based on intelligent WCA-ELM in the Three Gorges Reservoir Area," Natural Harzard, vol. 107, no. 2, pp. 1709-1729, 2021.

[27] R. Shakeri, A. Mesgouez, and G. Lefeuve-Mesgouez, "Transient response of a concrete tunnel in an elastic rock with imperfect contact," International Journal of Mining Science and Technology, vol. 30, no. 5, pp. 605-612, 2020.

[28] Y. Zhang, J. B. Qiu, Y. G. Zhang, and Y. L. Xie, "The adoption of a support vector machine optimized by GWO to the prediction of soil liquefaction," Environmental Earth Sciences, vol. 80, no. 9, 2021.

[29] Y.-g. Zhang, J. Tang, R.-p. Liao et al., "Application of an enhanced BP neural network model with water cycle algorithm on landslide prediction," Stochastic Environmental Research and Risk Assessment, vol. 35, no. 6, pp. 1273-1291, 2021. 
[30] L.-K. Chen, R.-P. Yuan, X.-J. Ji et al., "Modular composite building in urgent emergency engineering projects: a case study of accelerated design and construction of Wuhan Thunder God Mountain/Leishenshan hospital to COVID-19 pandemic," Automation in Construction, vol. 124, Article ID 103555, 2021.

[31] L.-K. Chen, P. Liu, L.-M. Zhu, J.-B. Ding, Y.-L. Feng, and F. Moreu, "A simplified iterative approach for testing the pulse derailment of light rail vehicles across a viaduct to nearfault earthquake scenarios," Proceedings of the Institution of Mechanical Engineers - Part F: Journal of Rail and Rapid Transit, Article ID 095440972098741, 2021.

[32] B. H. Fellenius, "The analysis of results from routine pile load tests," Ground Engineering, vol. 13, no. 6, pp. 19-31, 1980.

[33] B. H. Fellenius, A. J. O’Brien, R. E. Riker et al., "Dynamic monitoring and conventional pile testing procedure," $A$ Program Presented in Symposium Dynamic Measurement of Piles and Piers, pp. 1-24, 1983.

[34] G. Holm, M. Jansson, and B. Moller, "Dynamic and static load testing of friction piles in loose sand," in Proceedings of the 2nd International Conference on the Application of Stress Wave Theory to Pile Foundation, pp. 240-243, Stockholm, Sweden, May 1984.

[35] C. D. Thompson and G. Goble, "High case damping constants in sand," in Proceedings Of the 3rd International Conference On the Application Of Stress Wave Theory To Pile Foundation, pp. 555-556, Ottawa, Canada, May 1988.

[36] P. K. Wong, "The use of pile driving analyzer at a hospital complex in Malaysia," in Proceedings of the 3rd International Conference on the Application of Stress Wave Theory to Pile Foundation, pp. 762-770, Ottawa, Canada, May 1988.

[37] F. Chen, "FEIPWAPC pile wave analysis program using characteristics," Chinese Journal of Geotechnical Engineering, vol. 12, no. 5, pp. 65-75, 1990.

[38] J. Zai, "Pile dynamic testing experiences in Shanghai," in Proceedings Of the $3 r$ International Conference On the Application Of Stress Wave Theory To Pile Foundation, pp. 781-792, Ottawa, Canada, May 1988.

[39] K. Liwen, "PDA-case dynamic pile test study," Chinese Journal of Geotechnical Engineering, vol. 13, no. 2, pp. 41-50, 1991.

[40] Q. Ju, "Determination of bearing capacity of single pile by CASE method of high strain dynamic test pile," Geotechnical Engineering, vol. 5, no. 2, pp. 34-39, 1993.

[41] Z. Wu, Development and Application of PDA Power Test Pile Method in Guangdong," Pile Foundation Album, pp. 540-542, Shanxi University Union Press, Taiyuan, China, 1992.

[42] L. Zhang and J. Sun, "Dynamic measurement and CAPWAPC analysis of large diameter overlong pile in shanghai Area," in Proceedings of the 1990 Proceedings Of the Workshop on PDA Development Applications, pp. 280-296, Shanghai, China, 1990.

[43] D. Li, "On the Application Limitations of High Strain Dynamic Test Pile Method," Testing Technology Of Pile Foundation Engineering, pp. 88-95, China Building Materials Industry Press, Beijing, China, 1993.

[44] L. Xie, "An analysis on the nature of CASE method and on the cause of underestimated pile load capacity by this method," Chinese Journal of Geotechnical Engineering, vol. 21, no. 1, pp. 46-51, 1999.

[45] P. To and I. M. Smith, "A note on finite element simulations of pile driving," International Journal for Numerical and Analytical Methods in Geomechanics, vol. 12, no. 2, pp. 213-219, 1988.
[46] S. Tchepak, "Dynamic and sonic pile integrity testing-A contractor's experience," ", in Proceedings of the 4th International Conference on the Application of Stress Wave Theory to Pile Foundation, pp. 339-344, Hague, Netherlands, September 1992.

[47] S. G. Paikowsky and K. L. Stenersen, "The performance of the dynamic methods,their controlling parameters and deep foundation specifications," in Proceedings of the 6th International Conference on the Application of Stress Wave Theory to Pile Foundation, pp. 281-304, SaoPaulo, Brazil, September 2000.

[48] Committee of Soil Dynamics, Application Case and Analysis of Soil Dynamic Engineering, China Construction Industry Press, Beijing, China, 1998.

[49] G. Molloy, Regression Analysis and Linear Models, Larsen and Keller, New York, NY, USA, 2018. 